\section{Proximal Humerus Fractures in the Elderly: Concomitant Fractures and Management}

Kelly Zachariasen, M.D. ${ }^{1}$, Bradley R. Dart, M.D. ${ }^{1}$, Elizabeth Ablah, Ph.D., $\mathrm{MPH}^{2}$, Kelly Lightwine, $\mathrm{MPH}^{3}$, James Haan, M.D. ${ }^{1,3}$

University of Kansas School of Medicine-Wichita, Kansas

${ }^{1}$ Department of Surgery

${ }^{2}$ Department of Population Health

${ }^{3}$ Ascension Via Christi Hospital on St. Francis, Department of Trauma Services, Wichita, KS

Received Nov. 8, 2019; Accepted for publication Feb. 24, 2020; Published online May 21, 2020

\section{ABSTRACT}

Introduction. The purpose of this study was to identify additional injuries commonly seen with proximal humerus fractures experienced by patients 65 years or older and to evaluate discrepancies in the management of these patients with regard to provider type.

Methods. A retrospective review was conducted of all patients 65 years or older who sustained a proximal humerus fracture. Patient data collected included demographics, injury details, hospital course, and discharge destination.

Results. Patients with a concomitant fracture $(45.5 \%, \mathrm{n}=65)$ had a slightly higher Injury Severity Score (ISS; $8.3 \pm 3.0$ vs. $6.4 \pm 3.0$, p < $0.001)$ and experienced one additional death than those with an isolated fracture $(54.5 \%, \mathrm{n}=78)$. Slightly more patients were managed by a trauma provider $(51.7 \%, \mathrm{n}=74)$ than by a non-trauma provider $(48.3 \%, \mathrm{n}=69)$. Those managed by a trauma provider sustained the most pelvic fractures ( $12.2 \%$ vs. $2.9 \%, \mathrm{p}=0.038)$, were more likely to be injured in a motor vehicle collision ( $8.1 \%$ vs. $0 \%, \mathrm{p}=0.005)$, had a higher ISS ( $8.0 \pm 3.3$ vs. $6.4 \pm 2.8, \mathrm{p}=0.003$ ), and had more imaging performed than those treated by a non-trauma provider. There was, however, no difference in operative rates, concomitant injuries, length of stay, or discharge disposition regarding provider type.

Conclusion. It is important to recognize proximal humerus fractures as a sign of fragility and to optimize hospital management of these patients. Kans J Med 2020;13:101-105

\section{INTRODUCTION}

Falls are the leading cause of injury in adults aged 65 or older with an estimated 300,000 fall-related hospitalizations in the United States each year. ${ }^{1}$ Among this age group, one out of five falls results in a severe injury, with $94 \%$ of fractures being fall-related., ${ }^{1,2}$ Proximal humerus fractures are the third most common fracture in this age group, with an annual incidence of 25.3 per 10,000 person-years. ${ }^{3,4}$ Leading risk factors for a proximal humerus fracture are bone fragility and risk of falling. ${ }^{5}$ With an aging population, proximal humerus fractures will become an even more commonly encountered injury seen in emergency departments and trauma centers. ${ }^{6}$

Elderly patients who experience a proximal humerus fracture often have additional injuries or comorbid conditions, such as diabetes, depression, or dementia. ${ }^{5}$ In addition, proximal humerus fractures among the elderly can result in various complications, such as prolonged hospitalization and increased risk of future fractures.? Mortality among those 65 years or older who sustain a proximal

\section{KANSAS JOURNAL of MEDICINE}

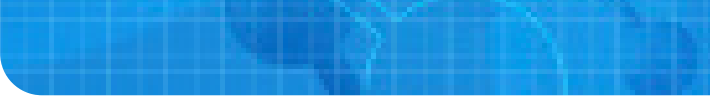

humerus fracture is 100 per 1,000 person-years. ${ }^{8}$

There has been little research on nonsurgical treatment and concomitant injuries seen in elderly patients who sustain a proximal humerus fracture. Most studies focused on operative management and functional outcomes. ${ }^{9-15}$ However, studies that mention associated injuries and diagnostic imaging usually concentrated on the affected shoulder girdle and did not extend beyond the scope of the injured area. ${ }^{9-15}$ For instance, one particular study found that $11.9 \%$ of elderly patients with a proximal humerus fracture also had a concomitant fracture, but the type or location of the additional fracture was not expounded. ${ }^{8}$

The purpose of this study was to identify additional injuries commonly seen with proximal humerus fractures experienced by patients 65 years or older and to evaluate discrepancies in the management of these patients with regard to provider type. Specifically of interest were differences seen between providers based on initial imaging studies performed, operative rates, length of hospital stay, and where patients were discharged.

\section{METHODS}

A retrospective chart review was conducted of all patients 65 years or older who sustained a proximal humerus fracture and were admitted to an American College of Surgeons-verified level-1 trauma center between January 1, 2001 and December 31, 2015. Proximal humerus fractures included a diagnostic ICD9 code of 812.0 - 812.09 or 812.1 - 812.19. The 2018 Compendium also was later referenced regarding what constitutes a proximal humerus fracture. ${ }^{16}$ To evaluate patients with only minor injuries, those with a Injury Severity Score (ISS) greater than 15 were excluded. Data collection included demographics (age, gender, and race), mechanism of injury, ISS, injury details (ipsilateral and concomitant fractures), need for surgery, initial imaging details, hospital length of stay (HLOS), disposition, and mortality.

Any injury-related imaging obtained within 24 hours of the patient's arrival or any prior imaging from a transferring hospital was considered as initial imaging. Fractures defined as concomitant excluded the shoulder girdle. Providers were defined as either trauma or non-trauma providers. Trauma providers included fellowship trained trauma surgeons and rotating trauma residents that respond to any trauma activations and trauma consults. A non-trauma provider included patients managed by orthopedic surgeons, family physicians, emergency physicians, or internal medicine physicians. Descriptive analyses were presented as frequencies with percentages for categorical variables and means with standard deviations for continuous variables. Independent sample t-tests were used to explore mean differences between continuous variables where Chi-square tests were used to assess the distributions of categorical variables. Prior to performing comparative analysis, patients were grouped by fracture type (concomitant vs. isolated) and by provider (non-trauma vs. trauma). 
KANSAS JOURNAL of MEDICINE ELDERLY PROXIMAL HUMERUS FRACTURES continued.

All statistical tests were two-sided and analyses were considered significant when the resultant $p$ value was $\leq 0.05$. All analyses, except where noted, were conducted using SPSS release 23.0 (IBM Corp., Armonk, New York). The study was approved by the Institutional Review Board of Via Christi Hospitals Wichita, Inc. and the Human Subjects Committee at the University of Kansas School of MedicineWichita.

\section{RESULTS}

A total of 177 patients were identified from the trauma registry. However, 34 patients were excluded since they had an ISS greater than 15 . Of the remaining 143 patients, most were female $(77.6 \%, \mathrm{n}=$ 111) and Caucasian $(95.1 \%, \mathrm{n}=136)$, with an average age of $80 \pm 8.2$ years and ISS of $7.3 \pm 3.1$. Most fractures were fall-related $(93.0 \%$, $\mathrm{n}=133$ ), and none of the patients sustained a spleen, liver, kidney, pancreas, or hollow viscus injury.

Forty-five percent $(\mathrm{n}=65)$ of patients sustained a concomitant fracture and $54.5 \%(\mathrm{n}=78)$ experienced an isolated fracture (Table 1). Patients with a concomitant fracture had a slightly higher ISS (8.3 \pm 3.0 vs. $6.4 \pm 3.0, \mathrm{p}<0.001)$ and were more likely to be discharged to a rehabilitation center $(21.5 \%$ vs. $7.7 \%, \mathrm{p}=0.014)$ than those with an isolated proximal humerus fracture. There were no differences between fracture type regarding age, gender, mechanism of injury, operative rates, or hospital length of stay.

Slightly more patients were managed by a trauma provider (51.7\%, $\mathrm{n}=74)$ than by a non-trauma provider $(48.3 \%, \mathrm{n}=69$; Table 2$)$. No difference was noted regarding the frequency of concomitant fractures between the different treatment groups. However, those managed by a non-trauma provider experienced more frequent ipsilateral hip fractures (20.3\% vs. $5.4 \%, \mathrm{p}=0.007)$ and those managed by a trauma provider experienced more frequent pelvic fractures (12.2\% vs. $2.9 \%, \mathrm{p}=0.038$ ).

Patients managed by a trauma provider had a higher average ISS $(8.0 \pm 3.3)$ than those managed by a non-trauma provider $(6.4 \pm 2.8, \mathrm{p}$ $=0.003$; Table 3$)$. In addition, all patients in a motor vehicle collision (MVC) were managed by a trauma provider ( $8.1 \%$ vs. $0 \%, \mathrm{p}=0.005)$, whereas patients injured in a fall were more likely to be managed by a non-trauma provider ( $98.6 \%$ vs. $85.1 \%, \mathrm{p}=0.002)$. There was no difference between the provider groups regarding average age, the frequency of concomitant fractures, operative management, hospital length of stay, or discharge disposition.

Among all patients, computed tomography (CT) was most likely performed of the cervical spine $(46.2 \%, \mathrm{n}=66)$ or the head $(43.4 \%$, $\mathrm{n}=62$; Table 4$)$. Most axial X-rays were to the chest $(68.5 \%, \mathrm{n}=98)$ and most non-axial $\mathrm{X}$-rays were to the shoulder of injury site $(96.5 \%$, $\mathrm{n}=138$; Tables 5 and 6). Patients managed by a trauma provider were more likely to receive additional imaging, particularly CT imaging of the head, spine, chest, abdomen, and the affected upper extremity (Table 4). Trauma providers also performed more axial X-rays of the chest, pelvis, and the cervical spine than those managed by a non-trauma provider (Table 5). Nonaxial X-ray imaging was similar between provider types except for the ipsilateral hip and ankle (Table 6).

Table 1. Comparison of demographics and injury severity of patients with proximal humerus fractures based on fracture.

\begin{tabular}{|l|c|c|c|}
\hline Parameter* & $\begin{array}{c}\text { Concomitant } \\
\text { Fracture }\end{array}$ & Isolated Fracture & $\begin{array}{c}\text { p } \\
\text { value }\end{array}$ \\
\hline Number of patients & $65(45.5 \%)$ & $78(54.5 \%)$ & \\
\hline Age (years) & $78 \pm 8.5$ & $80 \pm 8.0$ & 0.225 \\
\hline Female sex & $49(75.4 \%)$ & $62(79.5 \%)$ & 0.558 \\
\hline $\begin{array}{l}\text { Injury Severity Score } \\
\text { (ISS) }\end{array}$ & $8.3 \pm 3.0$ & $6.4 \pm 3.0$ & $<0.001$ \\
\hline Mechanism of injury & $58(89.2 \%)$ & $75(96.2 \%)$ & 0.106 \\
\hline Fall & $5(7.7 \%)$ & $3(3.8 \%)$ & 0.319 \\
\hline Motor vehicle collision & $15(23.1 \%)$ & $24(30.8 \%)$ & 0.304 \\
\hline $\begin{array}{l}\text { Surgery (proximal } \\
\text { humerus) }\end{array}$ & $5.6 \pm 4.0$ & $4.5 \pm 2.8$ & 0.073 \\
\hline $\begin{array}{l}\text { Hospital length of stay, } \\
\text { days }\end{array}$ & $32(49.2 \%)$ & $32(42.3 \%)$ & 0.014 \\
\hline Disposition & $14(21.5 \%)$ & $2(2.6 \%)$ & \\
\hline $\begin{array}{l}\text { Home, home with } \\
\text { health care }\end{array}$ & $3(4.6 \%)$ & $37(47.4 \%)$ & \\
\hline Rehabilitation & \begin{tabular}{l}
$6(7.7 \%)$ \\
\hline $\begin{array}{l}\text { Nursing home, skilled } \\
\text { nursing }\end{array}$
\end{tabular} & & \\
\hline Hospice, death & $32 \%)$ & \\
\hline
\end{tabular}

*Values presented as number (\%) or mean \pm standard deviation.

Table 2. Concomitant fractures among patients with proximal humerus fractures based on provider.

\begin{tabular}{|l|c|c|c|c|}
\hline Parameter ${ }^{*}$ & Total & Trauma & Non-Trauma & $\begin{array}{c}\text { p } \\
\text { value }\end{array}$ \\
\hline Number of patients & $143(100 \%)$ & $74(51.7 \%)$ & $69(48.3 \%)$ & \\
\hline $\begin{array}{l}\text { Concomitant } \\
\text { fractures }\end{array}$ & $65(45.5 \%)$ & $38(51.4 \%)$ & $27(39.1 \%)$ & 0.142 \\
\hline $\begin{array}{l}\text { Ipsilateral upper } \\
\text { extremity }\end{array}$ & $19(13.3 \%)$ & $10(13.5 \%)$ & $9(13.0 \%)$ & 0.934 \\
\hline Ipsilateral hip & $18(12.6 \%)$ & $4(5.4 \%)$ & $14(20.3 \%)$ & 0.007 \\
\hline Pelvis & $11(7.7 \%)$ & $9(12.2 \%)$ & $2(2.9 \%)$ & 0.038 \\
\hline Ipsilateral femur & $8(5.6 \%)$ & $6(8.1 \%)$ & $2(2.9 \%)$ & 0.277 \\
\hline $\begin{array}{l}\text { Lower extremities } \\
\text { (excluding } \\
\text { ipsilateral hip/ } \\
\text { femur) }\end{array}$ & $7(4.9 \%)$ & $4(5.4 \%)$ & $3(4.3 \%)$ & 1.000 \\
\hline Spine & $6(4.2 \%)$ & $5(6.8 \%)$ & $1(1.4 \%)$ & 0.211 \\
\hline Facial bones & $5(3.5 \%)$ & $3(4.1 \%)$ & $2(2.9 \%)$ & 1.000 \\
\hline Ribs & $4(2.8 \%)$ & $4(5.4 \%)$ & $0(0.0 \%)$ & 0.121 \\
\hline $\begin{array}{l}\text { Contralateral } \\
\text { upper extremity }\end{array}$ & $3(2.1 \%)$ & $1(1.4 \%)$ & $2(2.9 \%)$ & 0.609 \\
\hline
\end{tabular}

*Values presented as number (\%).

†More than one patient could have more than one fracture. 
Table 3. Comparison of demographics and injury severity of patients with proximal humerus fractures based on provider.

\begin{tabular}{|l|c|c|c|}
\hline Parameter & Trauma & Non-Trauma & p value \\
\hline Number of patients & $74(51.7 \%)$ & $69(48.3 \%)$ & \\
\hline Age (years) & $79 \pm 8.4$ & $80 \pm 8.0$ & 0.346 \\
\hline Female & $53(71.6 \%)$ & $58(84.1 \%)$ & 0.056 \\
\hline Injury Severity Score (ISS) & $8.0 \pm 3.3$ & $6.4 \pm 2.8$ & 0.003 \\
\hline Concomitant fracture & $38(51.4 \%)$ & $27(39.1 \%)$ & 0.142 \\
\hline Mechanism of injury & & & \\
\hline Fall & $64(85.1 \%)$ & $69(98.6 \%)$ & 0.002 \\
\hline Motor vehicle collision & $8(8.1 \%)$ & $0(0.0 \%)$ & 0.005 \\
\hline Surgery (proximal humerus) & $17(23.0 \%)$ & $22(31.9 \%)$ & 0.232 \\
\hline Hospital length of stay, days & $5.2 \pm 3.9$ & $4.8 \pm 2.8$ & 0.940 \\
\hline Disposition & & & 0.870 \\
\hline Home, home with health care & $29(39.2 \%)$ & $24(34.8 \%)$ & \\
\hline Rehabilitation & $9(12.2 \%)$ & $11(15.9 \%)$ & \\
\hline Nursing home, skilled nursing & $33(44.6 \%)$ & $32(46.4 \%)$ & \\
\hline Hospice, death & $3(4.1 \%)$ & $2(2.9 \%)$ & \\
\hline
\end{tabular}

*Values presented as number $(\%)$ or mean \pm standard deviation.

Table 4. Comparison of $\mathrm{C} T$ imaging frequency of patients with proximal humerus fractures based on provider.

\begin{tabular}{|l|c|c|c|c|}
\hline Parameter* & $\begin{array}{c}\text { Total } \\
\text { Population }\end{array}$ & Trauma & Non-Trauma & p value \\
\hline $\begin{array}{l}\text { Number of } \\
\text { patients }\end{array}$ & $143(100 \%)$ & $74(51.7 \%)$ & $69(48.3 \%)$ & \\
\hline C-spine & $66(46.2 \%)$ & $50(67.6 \%)$ & $16(23.2 \%)$ & $<0.001$ \\
\hline Head & $62(43.4 \%)$ & $37(50.0 \%)$ & $25(36.2 \%)$ & 0.001 \\
\hline $\begin{array}{l}\text { Affected upper } \\
\text { extremity }\end{array}$ & $24(16.8 \%)$ & $21(28.4 \%)$ & $3(4.3 \%)$ & $<0.001$ \\
\hline L-spine & $20(13.9 \%)$ & $17(22.9 \%)$ & $3(4.3 \%)$ & 0.001 \\
\hline T-spine & $18(12.6 \%)$ & $17(22.9 \%)$ & $1(1.4 \%)$ & $<0.001$ \\
\hline Pelvis & $18(12.6 \%)$ & $12(16.2 \%)$ & $6(8.7 \%)$ & 0.175 \\
\hline Maxillofacial & $7(4.9 \%)$ & $5(6.8 \%)$ & $2(2.9 \%)$ & 0.285 \\
\hline Abdomen & $6(4.2 \%)$ & $6(8.1 \%)$ & $0(0.0 \%)$ & 0.016 \\
\hline Chest & $6(4.2 \%)$ & $6(8.1 \%)$ & $0(0.0 \%)$ & 0.016 \\
\hline CTA chest & $2(1.4 \%)$ & $1(1.4 \%)$ & $1(1.4 \%)$ & 0.960 \\
\hline CTA pelvis & $1(0.7 \%)$ & $1(1.4 \%)$ & $0(0.0 \%)$ & 0.333 \\
\hline
\end{tabular}

*Values presented as number (\%).

Table 5. Comparison of axial X-ray frequency of patients with proximal humerus fractures based on provider.

\begin{tabular}{|l|c|c|c|c|}
\hline Parameter $^{*}$ & Total Population & Trauma & Non-Trauma & $\begin{array}{c}\text { p } \\
\text { value }\end{array}$ \\
\hline $\begin{array}{l}\text { Number of } \\
\text { patients }\end{array}$ & $143(100 \%)$ & $74(51.7 \%)$ & $69(48.3 \%)$ & \\
\hline Chest & $98(68.5 \%)$ & $64(86.5 \%)$ & $34(49.3 \%)$ & $<0.001$ \\
\hline Pelvis & $85(59.4 \%)$ & $60(81.1 \%)$ & $25(36.2 \%)$ & $<0.001$ \\
\hline C-spine & $8(5.6 \%)$ & $7(9.5 \%)$ & $1(1.4 \%)$ & 0.037 \\
\hline L-spine & $5(3.5 \%)$ & $3(4.1 \%)$ & $2(2.9 \%)$ & 0.943 \\
\hline $\begin{array}{l}\text { Flexion/ } \\
\text { extension }\end{array}$ & $4(2.8 \%)$ & $3(4.1 \%)$ & $1(1.4 \%)$ & 0.345 \\
\hline T-spine & $4(2.8 \%)$ & $3(4.1 \%)$ & $1(1.4 \%)$ & 0.345 \\
\hline Lumbosacral & $3(2.1 \%)$ & $2(2.7 \%)$ & $1(1.4 \%)$ & 0.593 \\
\hline
\end{tabular}

*Values presented as number (\%).
KANSAS JOURNAL of MEDICINE ELDERLY PROXIMAL HUMERUS FRACTURES

continued.

Table 6. Comparison of non-axial X-ray frequency of patients with proximal humerus fractures based on provider.

\begin{tabular}{|c|c|c|c|c|}
\hline Parameter* & Total Population & Trauma & Non-Trauma & p value \\
\hline $\begin{array}{l}\text { Number of } \\
\text { patients }\end{array}$ & $143(100 \%)$ & $74(51.7 \%)$ & $69(48.3 \%)$ & \\
\hline $\begin{array}{l}\text { Shoulder } \\
\text { of humerus } \\
\text { (injury site) }\end{array}$ & $138(96.5 \%)$ & $71(95.9 \%)$ & $67(97.1 \%)$ & 0.707 \\
\hline \multicolumn{5}{|c|}{ Upper extremity ipsilateral } \\
\hline $\begin{array}{l}\text { Elbow joint } \\
\text { (below } \\
\text { injury) }\end{array}$ & $21(14.7 \%)$ & $13(18.3 \%)$ & $8(11.6 \%)$ & 0.313 \\
\hline Wrist & $18(12.6 \%)$ & $8(11.3 \%)$ & $10(14.5 \%)$ & 0.507 \\
\hline Forearm & $17(11.9 \%)$ & $12(16.9 \%)$ & $5(7.2 \%)$ & 0.98 \\
\hline Hand & $9(6.3 \%)$ & $6(8.5 \%)$ & $3(4.3 \%)$ & 0.355 \\
\hline Scapula & $2(1.4 \%)$ & $1(1.4 \%)$ & $1(1.4 \%)$ & 0.960 \\
\hline \multicolumn{5}{|c|}{ Upper extremity contralateral } \\
\hline Shoulder & $6(4.2 \%)$ & $4(5.4 \%)$ & $2(2.9 \%)$ & 0.455 \\
\hline Wrist & $4(2.8 \%)$ & $3(4.1 \%)$ & $1(1.4 \%)$ & 0.345 \\
\hline Hand & $2(1.4 \%)$ & $1(1.4 \%)$ & $1(1.4 \%)$ & 0.960 \\
\hline Elbow & $1(0.7 \%)$ & $1(1.4 \%)$ & $0(0.0 \%)$ & 0.333 \\
\hline Forearm & $1(0.7 \%)$ & $1(1.4 \%)$ & $0(0.0 \%)$ & 0.333 \\
\hline \multicolumn{5}{|c|}{ Lower extremity ipsilateral } \\
\hline Hip & $24(16.8 \%)$ & $7(9.5 \%)$ & $17(24.6 \%)$ & 0.015 \\
\hline Knee & $16(11.2 \%)$ & $10(13.5 \%)$ & $6(8.7 \%)$ & 0.361 \\
\hline Femur & $11(7.7 \%)$ & $8(10.8 \%)$ & $3(4.3 \%)$ & 0.147 \\
\hline Ankle & $4(2.8 \%)$ & $4(5.4 \%)$ & $0(0.0 \%)$ & 0.050 \\
\hline $\begin{array}{l}\text { Tibia/ } \\
\text { fibula }\end{array}$ & $2(1.4 \%)$ & $1(1.4 \%)$ & $1(1.4 \%)$ & 0.960 \\
\hline Foot & $1(0.7 \%)$ & $0(0.0 \%)$ & $1(1.4 \%)$ & 0.299 \\
\hline \multicolumn{5}{|c|}{ Lower extremity contralateral } \\
\hline Knee & $9(6.3 \%)$ & $7(9.5 \%)$ & $2(2.9 \%)$ & 0.106 \\
\hline Hip & $5(3.5 \%)$ & $3(4.1 \%)$ & $2(2.9 \%)$ & 0.707 \\
\hline Femur & $4(2.8 \%)$ & $3(4.1 \%)$ & $1(1.4 \%)$ & 0.345 \\
\hline Ankle & $2(1.4 \%)$ & $2(2.7 \%)$ & $0(0.0 \%)$ & 0.169 \\
\hline $\begin{array}{l}\text { Tibia/ } \\
\text { fibula }\end{array}$ & $1(0.7 \%)$ & $1(1.4 \%)$ & $0(0.0 \%)$ & 0.333 \\
\hline
\end{tabular}

*Values presented as number (\%).

\section{DISCUSSION}

The current study results indicated that concomitant fractures are common among elderly patients who sustain proximal humerus fractures, with nearly half of all patients sustaining a concomitant fracture. In comparison to previous studies, this incidence was much higher. ${ }^{17,18}$ For instance, Clement et al. ${ }^{17}$ cited $10 \%$ of patients had multiple fractures, and Neuhaus et al. ${ }^{18}$ reported $28 \%$ of patients had multiple fractures. Additional study results indicated that upper extremity, hip, and pelvic fractures commonly were associated with a proximal humerus fracture. These findings were consistent with an Italian study by Pedrazzoni et al. ${ }^{19}$ which also showed that the most 


\section{KANSAS JOURNAL of MEDICINE}

\section{ELDERLY PROXIMAL HUMERUS FRACTURES}

continued.

common simultaneous fractures are of the hip, distal radius, pelvis, and ribs.

The percentage of concomitant hip fractures in the current study was higher than had been reported previously. ${ }^{20-22}$ Di Monaco et al. ${ }^{21-22}$ studied patients with hip fractures and evaluated concomitant fractures; however, concomitant proximal humerus fractures ranged from $1.4 \%$ to $2.1 \%$. This discrepancy could be related to other factors, such as the degree of osteoporotic disease at the time of the fracture. Future research could be done to determine the unique characteristics of patients presenting with proximal humerus fractures and how best to manage them.

Studies of simultaneous hip and proximal humerus fractures have reported conflicting data regarding the length of stay. ${ }^{21-24}$ However, in the current study, there was no difference in hospital length of stay between patients with concomitant and isolated fractures. In addition, Neuhaus et al. ${ }^{18}$ demonstrated that adults with concomitant fractures and a proximal humerus fracture had an increase in adverse events and mortality, and a greater percent were discharged to a facility. In the current study, patients with concomitant fractures were more likely to require rehabilitation than those with isolated fractures.

Previous studies have suggested discrepancies in hospital management techniques among different providers regarding proximal humerus fractures and other types of fractures. ${ }^{24-26}$ In the current study, for instance, differences were noted with regard to the number of images obtained by provider type. These differences could be attributed to differences in injury mechanism. For example, all patients injured in an MVC were managed by a trauma provider. This was not surprising considering most MVC patients are transported by ambulance and are more likely to activate a trauma response. Although trauma providers ordered more imaging than non-trauma providers, there was no difference in the frequency of operative treatments between the two groups. Previous studies supported this finding by reporting that C'Ts do not affect treatment recommendations, specifically regarding operative vs. nonsurgical management. ${ }^{15,27}$

Patients treated at trauma centers typically have higher associated costs and more interventions than those treated at non-trauma centers with similar outcomes. ${ }^{28}$ Although we did not evaluate costs in this study, one could surmise that patients managed by a trauma provider accrued higher costs since these patients had more imaging performed than those managed by a non-trauma provider, even though they had similar operative rates and lengths of stay. The additional diagnostic modalities utilized by trauma providers could place a strain on the system and represent aggressive, labor-intensive management strategies that do not necessarily produce different patient outcomes.

There were several limitations of this study, including the weaknesses inherent in a retrospective study design. Additional limitations of this study included a small sample size, including patients from a single level 1 trauma center with few minorities represented, and including only patients with an ISS less than 15, which did not allow direct comparisons to most previous studies. In several cases that were analyzed, the patient was transferred from an outside hospital and had prior imaging at that hospital. Even though the medical provider likely had access to these initial images, these initial images were not available among patient medical records, therefore were not included. This could be a future area of research to compare elderly patients with multiple fractures to those with isolated fractures.

\section{CONCLUSIONS}

Concomitant fractures are common in elderly trauma patients who experience a proximal humerus fracture. Patients managed by trauma providers were more likely to be injured in an $\mathrm{MVC}$, have a higher ISS, experience more pelvic fractures, and have more imaging performed than those treated by non-trauma providers. Despite these differences, no differences in the frequency of operative treatments were observed between the different providers. It is important to recognize proximal humerus fractures as a sign of fragility and to optimize hospital management of these patients.

\section{REFERENCES}

${ }^{1}$ US Centers for Disease Control and Prevention. Home and recreational safety. Older adult falls: important facts about falls. October 11, 2016. https:// www.cdc.gov/homeandrecreationalsafety/falls/adultfalls.html. Accessed 26 April 2017.

${ }^{2}$ Olsson C, Nordqvist A, Petersson C. Increased fragility in patients with fracture of the proximal humerus: A case control study. Bone 2004; 34(6):1072-1077. PMID: 15193555.

${ }^{3}$ Baron JA, Barrett JA, Karagas MR. The epidemiology of peripheral fractures. Bone 1996; 18(3 Suppl):209S-213S. PMID: 8777090.

${ }^{4}$ Karl JW, Olson PR, Rosenwasser MP. The epidemiology of upper extremity fractures in the United States, 2009. J Orthop Trauma 2015; 29(8):e242-244. PMID: 25714441.

${ }^{5}$ Roux A, Decroocq L, El Batti S, et al. Epidemiology of proximal humerus fractures managed in a trauma center. Orthop Traumatol Surg Res 2012; 98(6):715-719. PMID: 23000039.

${ }^{6}$ Ortman JM, Velkoff VA, Hogan H. United States Census Bureau. An aging nation: The older population in the United States. 2014. https://www. census.gov/library/publications/2014/demo/p25-1140.html. Accessed 26 April 2017.

${ }^{7}$ Lubbeke A, Stern R, Grab B, Herrmann F, Michel JP, Hoffmeyer P. Upper extremity fractures in the elderly: Consequences on utilization of rehabilitation care. Aging Clin Exp Res 2005; 17(4):276-280. PMID: 16285192.

${ }^{8}$ Clement ND, Duckworth AD, McQueen MM, Court-Brown CM. The outcome of proximal humeral fractures in the elderly: Predictors of mortality and function. Bone Joint J 2014; 96-B(7):970-977. PMID: 24986953.

9 Slobogean GP, Johal H, Lefaivre KA, et al. A scoping review of the proximal humerus fracture literature. BMC Musculoskelet Disord 2015; 16:112. PMID: 25958203

10 Bahrs C, Rolauffs B, Südkamp NP, et al. Indications for computed tomography (CT) diagnostics in proximal humeral fractures: A comparative study of plain radiography and computed tomography. BMC Musculoskelet Disord 2009; 10:33. PMID: 19341472.

11 Foroohar A, Tosti R, Richmond JM, Gaughan JP, Ilyas AM. Classification and treatment of proximal humerus fractures: Inter-observer reliability and agreement across imaging modalities and experience. J Orthop Surg Res 2011; 6:38. PMID: 21801370.

12 Janssen SJ, Hermanussen HH, Guitton TG, van den Bekerom MP, van Deurzen DF, Ring D. Greater tuberosity fractures: Does fracture assessment and treatment recommendation vary based on imaging modality? Clin Orthop Relat Res 2016; 474(5):1257-1265. PMID: 26797912.

${ }^{13}$ Berkes MB, Dines JS, Little MT, et al. The impact of three-dimensional CT imaging on intraobserver and interobserver reliability of proximal humeral fracture classifications and treatment recommendations. J Bone Joint Surg Am 2014; 96(15):1281-1286. PMID: 25100775. 
14 Berkes MB, Dines JS, Birnbaum JF, et al. The axillary view typically does not contribute to decision making in care for proximal humeral fractures. HSS J 2015; 11(3):192-197. PMID: 26981052.

${ }^{15}$ Ramappa AJ, Patel V, Goswami K, et al. Using computed tomography to assess proximal humerus fractures. Am J Orthop (Belle Mead NJ) 2014; 43(3):43-47. PMID: 24660183.

${ }^{16}$ Meinberg EG, Agel J, Roberts CS, Karam MD, Kellam JF. Fracture and dislocation classification compendium - 2018. J Orthop Trauma 2018; 32(Suppl 1):Sl-S170. PMID: 29256945.

${ }_{17}$ Clement ND, Aitken S, Duckworth AD, McQueen MM, Court-Brown CM. Multiple fractures in the elderly. J Bone Joint Surg Br 2012; 94(2):231236. PMID: 22323692.

18 Neuhaus V, Swellengrebel CHJ, Bossen JKJ, Ring D. What are the factors influencing outcome among patients admitted to a hospital with a proximal humeral fracture? Clin Orthop Relat Res Clinical 2013; 471(5):1698-1706. PMID: 23456187.

${ }_{19}$ Pedrazzoni M, Abbate B, Verzicco I, Pedrazzini A, Benatti M, Cervellin G. Humeral fractures due to low-energy trauma: An epidemiological survey in patients referred to a large emergency department in Northern Italy. Arch Osteoporos 2015; 10:228. PMID: 26198160.

${ }^{20}$ Robinson P, Harrison T, Cook A, Parker MJ. Orthopaedic injuries associated with hip fractures in those aged over 60 years: A study of patterns of injury and outcomes for 1971 patients. Injury 2012; 43(7):1131-1134. PMID: 22465517.

${ }^{21}$ Di Monaco M, Castiglioni C, Vallero F, Di Monaco R, Tappero R. Concomitant upper limb fractures and short-term functional recovery in hip fracture patients: Does the site of upper limb injury matter? Am J Phys Med Rehabil 2015; 94(5):366-372. PMID: 25251255.

22 Di Monaco M, Vallero F, Di Monaco R, Mautino F, Cavanna A. Functional recovery after concomitant fractures of both hip and upper limb in elderly people. J Rehabil Med 2003; 35(4):195-197. PMID: 12892247.

${ }_{23}$ Mulhall KJ, Ahmed A, Khan Y, Masterson E. Simultaneous hip and upper limb fracture in the elderly: Incidence, features, and management considerations. Injury 2002; 33(1):29-31. PMID: 11879829.

${ }^{24}$ Bhat SB, Secrist ES, Austin LS, et al. Displaced proximal humerus fractures in older patients: Shoulder surgeons versus traumatologists. Orthopedics 2016; 39(3):509-513. PMID: 27135449.

${ }^{25}$ Kwon JY, Diwan A, Susarla S, Chacko AT, Rodriguez EK. Effect of surgeon training, fracture, and patient variables on calcaneal fracture management. Foot Ankle Int 2011; 32(3):262-27l. PMID: 21477545.

26 Gardner MJ, Streubel PN, McCormick JJ, Klein SE, Johnson JE, Ricci WM. Surgeon practices regarding operative treatment of posterior malleolus fractures. Foot Ankle Int 2011; 32(4):385-393. PMID: 21733441.

27 Jacquot A, Poussange N, Charrissoux JL, et al. Usefulness and reliability of two- and three-dimensional computed tomography in patients older than 65 years with distal humerus fractures. Orthop Traumatol Surg Res 2014; 100(3):275-280. PMID: 24709303.

28 Staudenmayer KL, Hsia RY, Mann NC, Spain DA, Newgard CD. Triage of elderly trauma patients: A population-based perspective. J Am Coll Surg 2013; 217(4):569-576. PMID: 24054408.

Keywords: humeral fractures, elderly, injuries, diagnostic imaging
KANSAS JOURNAL of MEDICINE ELDERLY PROXIMAL HUMERUS FRACTURES continued. 